\title{
The Application of Strengths, Weaknesses, Opportunities and Threats (SWOT) Analysis and the Role of Farmers Research Group (FRG) in Agricultural Technology Adoption and Dissemination Case Study in the Central Highlands of Oromia Ethiopia
}

\author{
Ayalew Adela \\ Ethiopian Institute of Agricultural Research (EIAR), Holetta Agricultural Research Center (HARC), P.O.Box \\ 2003, Addis Ababa, Ethiopia
}

\begin{abstract}
This paper presents the role, strengths, weaknesses, opportunities, and threats of FRG in agricultural technologies adoption and dissemination in the central highlands of western Shewa Oromia Ethiopia. Two sub-districts were selected because of the presence of different FRGs. The objective of the study was to investigate FRG approach is an approach which helps farmers to adopt new agricultural technologies. Data were collected by multi-stage sampling methods SWOT analysis, group discussion; key informant interview, mapping and task analysis were employed for data analysis. A total of one hundred thirty (130), interviewers were participated as individual households and group discussion where 54 from FRG members and 76 non- members. Data were analyzed in qualitative and SWOT analysis. The Results of analysis reveal that roles of FRG were enhancing new agricultural technologies adoption and dissemination. As Strengths voluntary participation and organization, simple chain of command, improve interaction with group and strong linkage with agricultural researchers. As weakness documentation, recording and handling of data wear not well organized. As an opportunity policy and enabling policy of the country favored group work, non participant farmers show a tendency of organizing themselves by FRGs, availability of improved agricultural technologies and very positive mutual understanding and perception about agricultural researchers. As a threats there is no expected support from district agricultural office, less participation of stakeholders except agricultural researchers, very less women participation, no body take responsibility to access stable market.
\end{abstract}

Keywords: FRG, Agricultural technologies ,Adoption, Dissemination,

DOI: $10.7176 / \mathrm{JBAH} / 9-12-03$

Publication date:June $30^{\text {th }} 2019$

\section{Introduction}

Ethiopia is one of the least developed countries in the world with a total population of more than 100 million (CSA, 2019). Agriculture is the mainstay of the Ethiopian economy, contributing $41.4 \%$ of the country's gross domestic product (GDP), $83.9 \%$ of the total exports, and $80 \%$ of all employment in the country (Matousa, Todob, \& Mojoc, 2013).Increasing agriculture productivity is obviously a major immediate goal of any agricultural program. As a result, agricultural research and extension have been designed to stimulate 'development'. Hence, as Bunch (1991) has indicated most programs see their roles as that of teaching farmers a set of innovations that will increase productivity. Consequently, widespread dissemination of certain technologies, considered as perfect solutions to the problems studied by scientific researchers, was attempted for many decades. However, research and technology development policies have been criticized for being misguided and resulting in interventions that have failed to significantly improve low-external-input farming systems, as they focus mainly on high input agriculture (Chambers \& Jiggins 1986). On the other hand, Haverkort (1991) mentioned that, although largely unperceived by mainstream agriculturists, many farmers, sometimes supported by extension workers, have been developing sustainable farming techniques. Agricultural extension plays an important catalytic role in agricultural and rural development as it brings the farming community information and new technologies that can be adopted to improve production, incomes and standards of living. Agricultural extension provides a channel by which farmers' problems are identified for research and modification of agricultural policies.

Participatory research approach emerged as a response to the limitations of earlier top-down conventional agricultural research approach that often failed to deliver significant improvements in levels of well-being for the poor in complex, risk prone environments (Chambers et al, 1989).

One of the strategies currently adopted to form strong alliances with farmers in the process of making agricultural research and extension client oriented and demand-driven is the intervention of participatory agricultural research approaches like establishment of Farmers-Research-Groups (FRGs) approaches.

FRG approach is a research approach by which a multidisciplinary research team, extension workers and groups of farmers jointly conduct participatory on-farm agricultural research through need-based technology 
generation, adaptation and dissemination with the participation of other stakeholders on field days, visits, experience sharing and workshops (JICA, 2009).Farmers who have common problems and are voluntarily willing to work in a group would join the FRG approach. Often driven by food security and market forces, farmers in Ethiopia have been innovating for centuries. Even though innovation is not a new phenomenon to the smallholder farmers in Ethiopia, the research and development support given to them by the scholars was very low. Thus, the experience is indeed in its infancy but only in the last few years' innovation development as FRGs has started to tap into the existing social system as a means to adopt in research and development programs (Farrington and Martine, 1993; Kiflu and Berhanu, 2002).

The foregoing description of the emerging roles of extension services necessitated the analysis of extension organizations using the SWOT technique so as to highlight the areas need for improved performance. It will also identify areas where organizations need to re-position themselves for the future challenges. In SWOT analysis answers are provided to the questions on each of the four concepts whose first letter forms the acronym: Strengths (what advantages, area of excel, relevant resources possessed and strengths as perceived by people), Weaknesses (what to improve, area of poor performance, and area to avoid), and Opportunities (which are good and interesting trends of the organization.) Threats (which obstacles with the level of sophistication)

\section{RESEARCH METHODOLOGY}

\section{Description of the Study Area}

The study area Welmara district is found in western part of Oromia Region in Ethiopia $21 \mathrm{Km}$ from Addis Ababa capital city of Ethiopia study area is situated between $08^{0} 50^{\prime} 04^{\prime \prime} \mathrm{N}$ to $09^{\circ} 12^{\prime} 55^{\prime \prime} \mathrm{N}$ latitudes and $42^{\circ} 55^{\prime} 32^{\prime \prime} \mathrm{E}$ to $43^{\circ} 14^{\prime} 19^{\prime \prime}$ E longitudes and at altitude of 2390 masl.

\section{Sample size and sampling procedure}

Multi-stage sampling methods were employed. As a First step, welmera district and two sub districts (Telecho and IlalaGojo) were selected purposefully because of the presence of different FRGs operating in the sub district. Using non replaceable lottery method and proportional to size sampling techniques 54 FRG members and 76 non participant member farmers which, totally 130 samples were selected.

\section{Data Sources and Method of Data Collection}

Interview schedule and group discussions have been conducted to gather the information to strengthen the group discussion, key informants from respective stakeholders' institution i.e. districts Agricultural office expertise, Agricultural researchers which directly involve in organizing FRG, extension workers of the district and FRGs members and leaders were interviewed to know the strength and weakness of FRG approach SWOT analysis wear conducted.

\section{Data Analysis}

Data were analyzed using different methods and procedures of qualitative and SWOT analysis methods. Qualitative data collected using group discussion and key informant interview techniques and were analyzed using explanation.

\section{RESULTS AND DISCUSSION}

\section{The Roles of FRG in Enhancing agricultural technology Adoption}

As a result intrercaction and sharing of information, knowledge among farmers, extension workers and researchers to enhance adoption.FRG use as technology testing and dissemination lets farmers participate so that enables them to choose and adopted technologies suitable to their situations. The investegated FRG farmers have an apportunity to be part of agricaltural research and extension which was not considered in the conventional extension systems in the countory.The study examine and discusses to investigated FRGs followes the steps of agricaltural resrearch proceduer as follow.

\section{Problem Identification and Prioritization}

Active participation in Problem identification and prioritization is the starting point for the participation of FRG members once they are organized as a group. In the literature review part, it was stated that generally productivity and production of crop were low and in some instance before the intervation of FRG approch. Farmers always worried what to do with their low crop productivity and production. Collecting accurate information about the problem, need of the client, proper definition of the research problems and prioritization were a prerequisite. According to Ejigu and Pound (2002), This investigation result showed that so far FRG members can identified and prioritize their farm problem and make solution together with agricultural researchers

\section{Conducting Experimental trials on FRG members fields}

FRG under review have been engaged in testing, selecting and disseminating improved technologies either initiated by FRG member farmers or released by agricultural research centers. Based on their farming problem farmers need improved agricultural technologies, agricultural researchers and farmers together find solution and pursue the adoptability of new technologies.

The result of the group discussion showed that, FRG members conducted on- farm trials on their farm plot 
are not interested because of shortage of farm land if they are decided, farmers need compensation (rent) to their plot which is occupied by different on farm experimental trial by agricultural researchers.

Scaling up of technologies

FRG members not only select the good performed technologies for adoption and dissemination but members also exchanged information about the new introduced technologies. Farmers Field-days are organized by agricultural researchers on FRG members ' Non -FRG member farmers are usually invited to the field-day events. FRG members explain how they conducted and managed their field and what outputs are expected from this intervention to the participants.

At time of Group Discussion all FRGs members agreed that information dissemination was high which ensures informal technology diffusion network among the groups, in adjacent villages and among the farming community to copy and disseminate new agricultural technologies. -participant farmers and

\section{Monitoring and evaluation}

Participatory monitoring and evaluation is one of the key activities of FRG approach. FRG evaluation exercise can prove a crucial research-extension activity not only to identify the strength or weakness and achievement of the group, but also to recognize the difficulties encountered in the day-to day activities and management of opportunities within the participatory process (Abera and Adam, 2001). The investigated FRGs Most of the time they were evaluated technologies together with respective agricultural researchers at different cropping stage but not as such planned evaluation monitoring and evaluation time.

\section{Linkage with researchers and agricultural extension workers}

The study focused mainly with the vital link to the successful agricultural technology development of FRG. FRG is a functional framework of research extension and farmer linkage which motivated farmers, researchers, extension institutions and other stakeholders that involve in participatory research, Direct linkage of researchers with the farmer through on - farm research activities has been used for testing, adopting, multiplying and disseminating improved technologies by the FRGs (Leeuwis, 2010).

In the study area, different institutions and social groups are working for socioeconomic development of individuals as well as the community which include; Agricultural research centers, NGOs District administrative council, FRGs, Women association, youth association, Micro finance Association, traders, brokers and input suppliers.

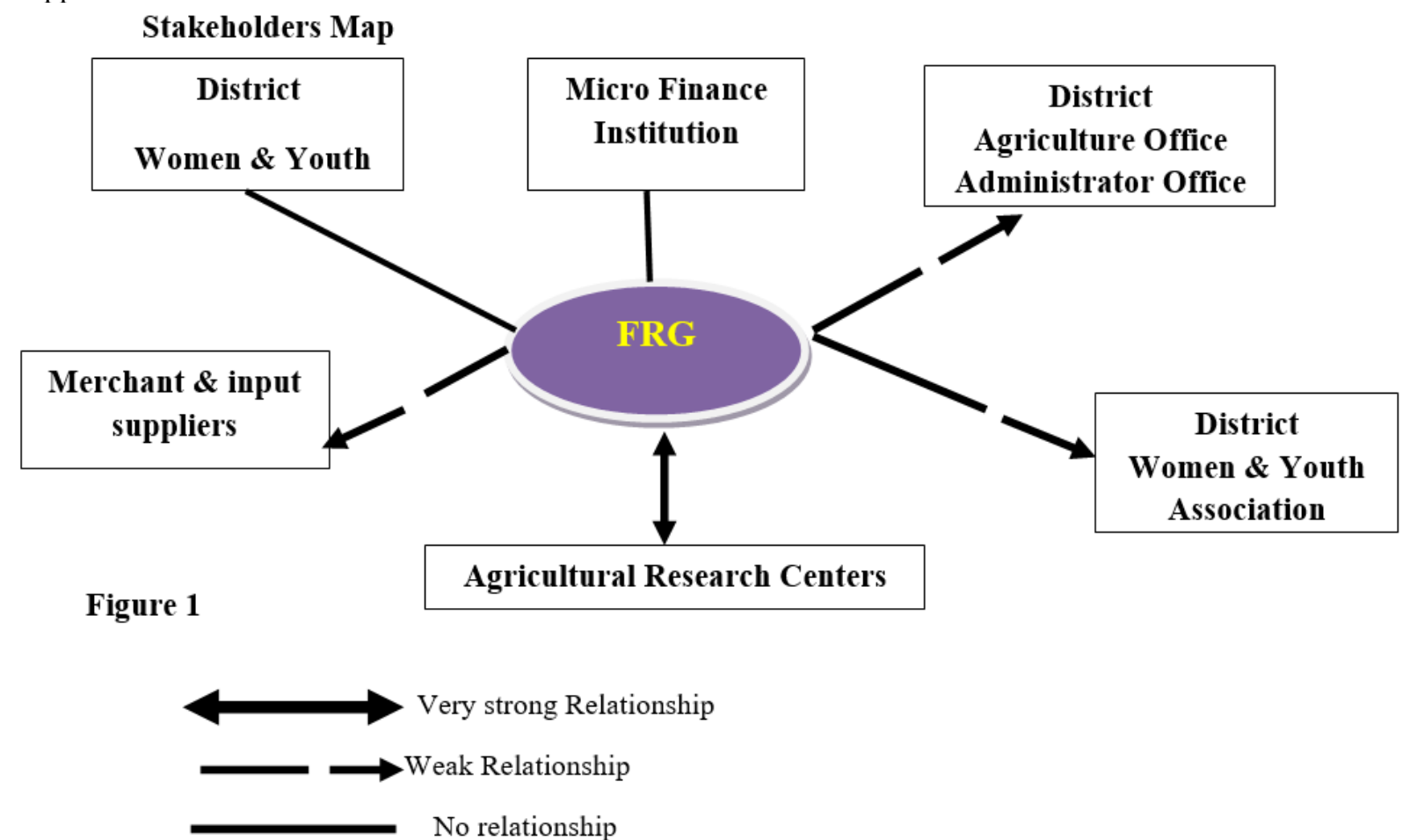

Participatory task analysis was conducted together with Agricultural researcher's team and agricultural extension workers team to assess the role, functions and division of task in the system task analysis helps to know the linkage between different stakeholders. 
Task analysis sheet

\begin{tabular}{|c|c|c|c|c|}
\hline List of Task & FRG & $\begin{array}{c}\text { District } \\
\text { Agricultural office }\end{array}$ & $\begin{array}{c}\text { District } \\
\text { Administration }\end{array}$ & $\begin{array}{c}\text { Agricultural Researchers \& } \\
\text { Extension workers }\end{array}$ \\
\hline Need Assessments & $*$ & & & $*$ \\
\hline Set priority & $*$ & & & $*$ \\
\hline Training & $*$ & $*$ & & $*$ \\
\hline $\begin{array}{ll}\text { Provide } & \text { improved } \\
\text { Technology } & \end{array}$ & & & & $*$ \\
\hline implementation & $*$ & & & $*$ \\
\hline Monitoring & $*$ & & & $*$ \\
\hline Evaluation & $*$ & & & $*$ \\
\hline Community Mobilization & & $*$ & $*$ & \\
\hline Field day organization & $*$ & $*$ & $*$ & $*$ \\
\hline
\end{tabular}

Figure 2

The result of mapping and task analysis shows that District and sub-district level partner of ADPLAC (Agricultural Development Partners Linkage Advisory Council) were not involved in FRGs activities FRG members actively create linkage in all aspect to agricultural researchers whereas district Agricultural office and extension workers creates linkage in the forms of participating in training, community mobilization at the time of field day. According to the investigated FRGs the result shows that they have a close and very strong linkage with agricultural researchers but has a weak linkage with extension workers Usually only the researchers and FRGs members participate in the need assessments, Setting priority, training, implementation, monitoring and evaluation of the improved technologies (Figure $1 \& 2$ )

FRG approach is generally gender responsive However, in these two FRGs there were limited membership of women's $(6.48 \%)$, but, noted that wives of the FRG members farmers are indirectly beneficiaries of the technologies since they are part and particles of the household.

During the group discussion with FRG members it was observed that farmers were proud of being FRG members since it enabled them to open their mind and become receptive to new introduced improved agricultural technologies.

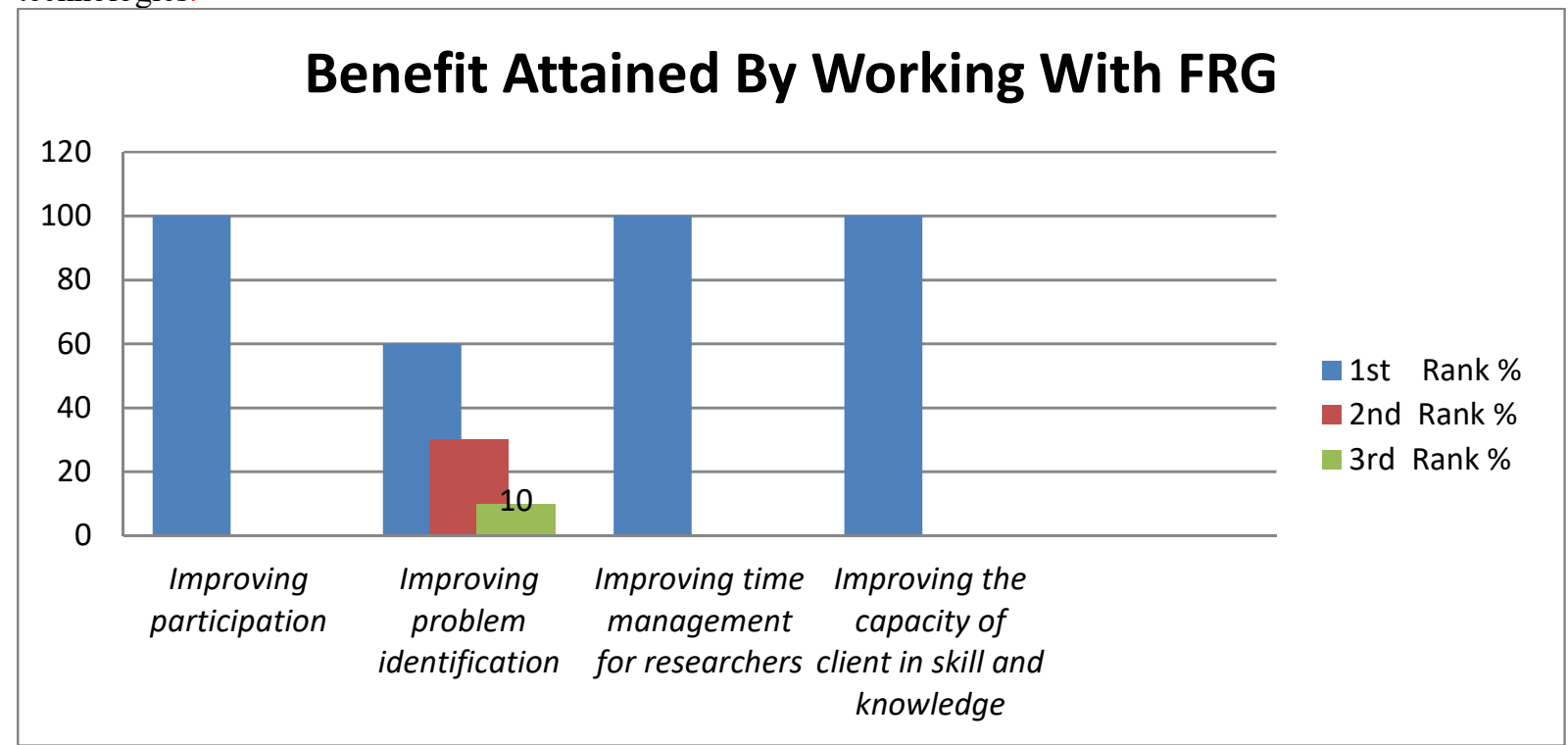

Figure 3

Ranking was done by multidisciplinary team indicate that $100 \%$ of the respondents reported that it improve participation of stakeholders. $60 \%$ agreed that it improved the problem identification capacity, $100 \%$ agreed to improve the time management of researchers and, $100 \%$ of them confirmed that it improve the capacity of client skill and knowledge (figure 3)

\section{Challenges working with FRG}

The investigated two FRGs cases there is very little recorded data and information. Only imperfect memory of the effort exists among the members. One of the two FRGs farmers started recording of data especially time of planting, wedding, chemical spraying, flowering and harvesting.

The survey result also showed that, $81 \%$ of the FRGs members reported that, they evaluated agricultural technologies by group around $60 \%$ of members reported that the leaders of FRG have a potential to lead and assisted the group, $80 \%$ of the respondent members stated that they reviewing they working plan specially planting 
calendar, $60 \%$ of the respondent farmers agree that farmers have enough meeting time and $100 \%$ of members farmers approve that they fell proud to be a member of the groups (Figure 4).

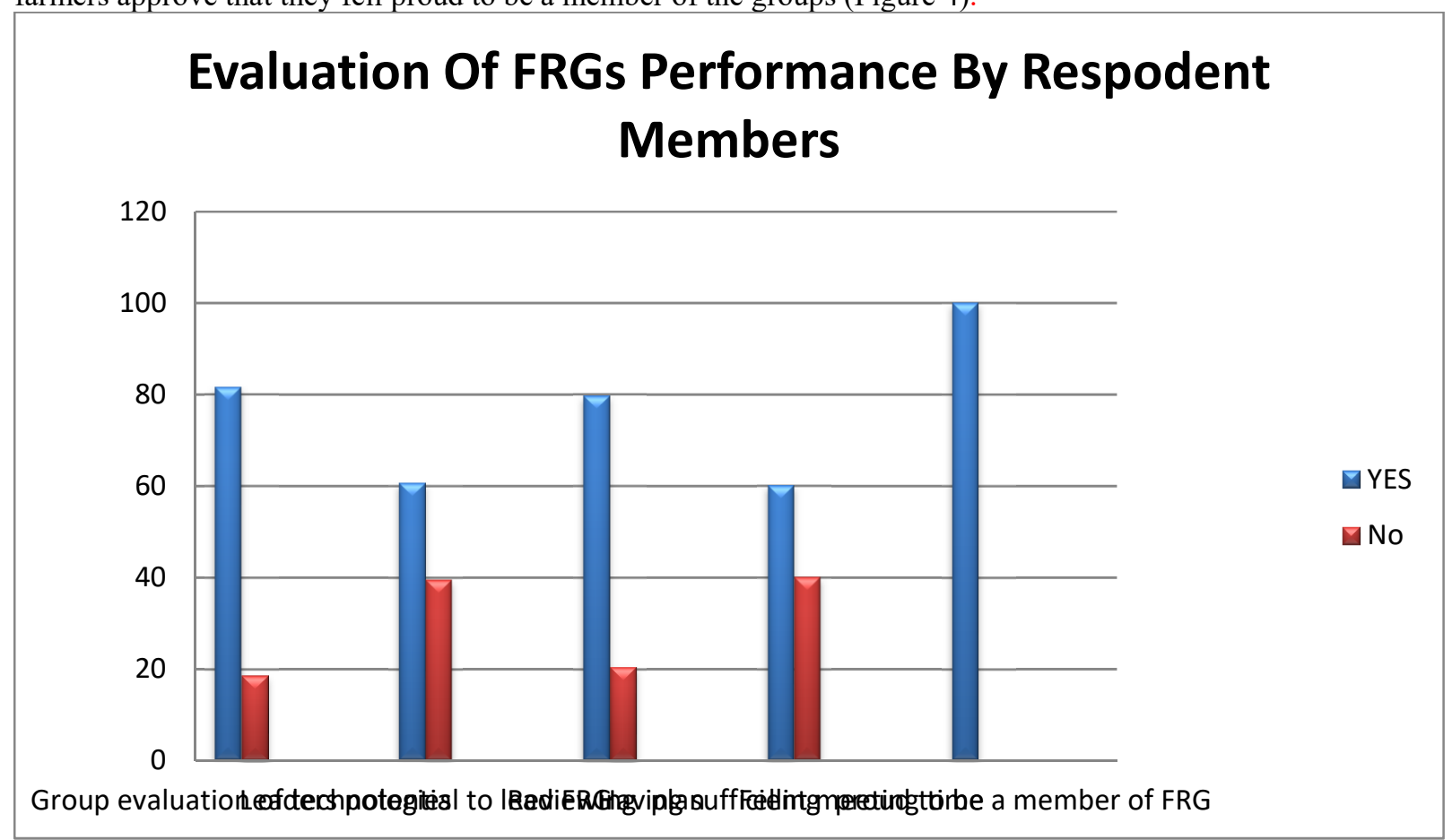

\section{Figure 4}

\section{SWOT ANALYSIS}

The result has been discussed accordingly into four sections: as the Strengths, Weaknesses, Opportunities and Threats. For the better comparison strengths and weakness of FRG have been categorized into three headings, namely "functional Structure", "Working Modality", "Implementation” With sub - headings.

\section{Strengths}

\section{A. Structure/organization of FRG}

Farmers in the district voluntarily organized themselves as a group to form FRG, members are interested and committed, Easy/simple chain of command, Encourages interaction among members and Inclusiveness of membership (gender, age, religion) .Voluntary organized by group create a positive ownerships sentiment of members.

Voluntary organized themselves without public interference was a fundamental approach to keep interested farmers to developed and keep demand driven technology generation and adoption.

\section{B. Working Modality}

Have agreed and commonly shared bylaws and guidelines, the members understood the modality of FRG, Democratically elect their leadership (chair person, secretary and treasurer) and Discussions are fully participatory and focus on major issues. Farmers work together in FRGs, important new skills are developed within the hamlets, like technical skills, skills in group management, problem solving, and economic cooperative, verbal expression and grassroots democracy.

\section{Implementation}

Investigated FRG make detailed operation of cropping calendar before each season. Everything has been planned in the calendar, responsibilities are assigned and a calendar of work is set up. Implementation based on their plan is executed i.e. Discussions are fully participatory and focus on major issues. before all the activities will be begin agricultural researchers gave training to all FRG members and they know when the field plow, purchasing of input, planting, harvesting, storing and annual farmers' field days organized to evaluate and select improved technologies

\section{Weaknesses}

\section{A. structure}

Inadequate recording and documenting of action, data and reports, nobody properly organized marketing activities and vale - chain to their product, brokers highly involved to sell farmers product which reduce the income of FRG members specially the investigated FRG members produce potato which is very perishable (short storage time) were some of the weakness of FRG structure. 


\section{B. Working Modality}

No regular meeting, Limited support from different stakeholders except agricultural researchers, training is not regularly (not time table) offered to the farmers, no proper arranged document at FRG office level (poor documentation). The members meet when things are happening and new information is came from different stakeholders' sudden calling of FRG members for meeting is not successful because members have other commitment so all member will not participate on unexpected meeting.

\section{Implementation}

Investigated FRGs leaders show a tendency to participate some special training without consulting members there is no regular training(refreshment) program handled by different stakeholders less follow up of different stakeholders except agricultural research center which is near to the district very less attention was given by district agricultural office and extension workers about implementation.

\section{Opportunities}

\section{A. Structure}

Policy and enabling policy of the government has prioritized agriculture as the top choice of the nation. Government committed to improved the level of income and quality life of the society, attain food self-sufficiency, build self-reliant and organized society based on the principles of voluntarism, favored group work, availability of improved agricultural technologies, Non participant farmers need to form new FRGs farmers in the district has a positive perception towards agricultural researches and extension workers long history of Ethiopian farmers in rural area have strong experienced working in a group .

\section{B. Working Modality}

Mutual understanding of agricultural researchers and farmers, practical trainings organized by agricultural researchers which farmers' voluntary participated, FRG members implemented and managed their Owen farm activities, the Proximity of agricultural research centers around the district which is working modality of farmers in the decision-making processes. Instead of relying only on external support Farmer becomes more confident in applying new techniques.

\section{Threats}

\section{A. Structure}

Inadequate support from district agricultural office, No support from appropriate stakeholders except agricultural researchers, less women participation and lack of an accountable body to acquire marketing issues of FRG, work was needed to involve major stakeholders, Market and value chain, Gender main steaming should come out as one of the major components of FRG which was not considered in the investigated FRG.

\section{Conclusion and Recommendation}

Implementing FRG approach would fasten improved agricultural technology evaluation, adoption and dissemination through farmers by dipping hard work and capital that has great implication on the prolonged and less participatory conventional research approach.These findings, farmers perceive FRG as proper extension approach in addressing the participation, need and concern of farmers. Respondents Participant farmers appreciating FRG in creating space for farmers views and experiences in the technology evaluation and dissemination. FRG has significant importance as technology evaluation, adoption and dissemination that can be considered as alternative extension approach with further improvements.

Group extension approach has been found the typical characteristics of FRG that contributed for the establishment of strong social bondage for the development of social capital among members. It is confirmed that group extension approach used under FRG has facilitate the knowledge sharing and learning process in the course of technology testing and evaluation. FRG has special focus on gender balance by providing equal opportunity for both sexes. However, the number of women in the investigated FRG is relatively low than men. From this findings of the study different stakeholder involvement is very less except agricultural researchers and extension workers but multi-disciplinary team participation is very crucial to strengthen FRG. From the findings and discussion it is found that FRG can be taken as an appropriate alternative extension approach with the following enrichment.

> Strong and aggressive work will be implemented to involve major respected stakeholders to institutionalize and scaling up of FRG approach.

$>$ Assess of market, value chine for their product should come out as one of the major components of FRG which was not considered at time of intervention of FRG approach.

$>$ Farmer-to-farmer dissemination and exchanging of information should be fostered and scaled up with committed involvement of district (community)-based organizations.

$>$ Improve women participation and ensure gender equality throughout the FRG approach must give emphasis.

> Capacity building of the FRGs members by formal and informal training needs to be give regularly

$>$ Promoting and facilitating access to education, research and information (radio) services; and strengthening and implementing the FRG research approach are some of this study suggested for future 
research, policy and development intervention points

\section{Reference}

Abera Adam, 2001, 'Participatory agricultural research process in eastern and central Ethiopia; using farmers€31 social network as entry point', Occasional publications series, No. 33, CIAT and Ethiopian Agricultural Research Organization, May 200

Abera, D., 2001. Conceptualization and history of people"s participation in research and development: Participatory research approaches and methodologies. Paper prepared for presentation of extension training workshop (un published). MARC, Melkassa, Ethiopia

Bunch, R. 1991. People centred agricultural development, in Haverkort, B., J. V. de Kamp and A. Water-Bayers (eds.), Joining farmers' experiences, London, IT Publications.

CSA, 2019. FDRE Central statistical Agency, Statistical Abstract for 2019. Addis Ababa, Ethiopia

Chambers, R., 1992, Rural Appraisal: Rapid, Relaxed and Participatory. IDS Discussion Paper 311, Brighton, University of Sussex.

Chambers, R. and J. Jiggins., 1986, Agricultural research for resource poor farmers: a parsimonious paradigm, IDS Discussion Paper 220, Brighton, University of Sussex.

Chambers, R., Pacey, A. and Thrupp, L.A., 1989. Farmer First: Farmer Innovation and Agricultural Research. London, Intermediate Technology Publications. pp.218

Ejigu, J. and Pound, B., 2002. Farmer participatory research end extension guideline. Institutionalization of Farmer Participatory Research (FPR) in the southern Nation and Nationality and People"s Regional State of Ethiopia. Institute for sustainable development, FARM Africa, Addis Ababa, Ethiopia

Farrington J, Martine A Farmer Participation in Agricultural Research: A review of concepts and practices. Occasional paper No 9. Overseas Development Institute, Regent's College, London (1993).

Haverkort, B., 1991, ' Farmers' experiments and participatory technology development' , in Haverkort, B., J. V. de Kamp and A. Water-Bayers (eds.), Joining farmers' experiences, IT Publications, London

Heemskerk W, Wennink B. Building Social Capital for Agricultural Innovation, Experiences with farmer groups in Sub-Saharan Africa, Bulletin 368. Royal Tropical Institute (KIT) - Amsterdam, 2004

Kiflu B and Berhanu K. Farmer Participatory Research: An Overview. Proceeding of client-Orient research evaluation workshop, 16-18 October 2001, Holetta Agricultural Research Center, Holetta, Ethiopia. EARO, Addis Ababa, Ethiopia, 2002, PP. 77-82.

Kiflu, B. and Berhanu, K., 2002. Farmer Participatory Research: An Overview. PP. 77-82. Proceeding of clientOrient research evaluation workshop, 16-18 October 2001, Holetta Agricultural Research Center, Holetta, Ethiopia. EARO, Addis Ababa, Ethiopia

Leeuwis, C., 2004 (forthcoming), Communication for innovation in agriculture and resource management: Building on the tradition of agricultural extension, Oxford, Blackwell Science.

Leeuwis, C., 2010. Communication for Rural innovation: rethinking Agricultural Extension.Third edition. CTA, Netherlands

Matousa, P., Todob, Y., \& Mojoc, D. (2013). Roles of extension and ethno-religious networks in acceptance of resource-conserving agriculture among Ethiopian farmers. International Journal of Agricultural Sustainability 11(4), 301-316.

Oakley, P., 1991, ' Projects with people: The practice of participation in rural development', Geneva, International Labour Office.

Pimentel, D. 1996. Green Revolution Agriculture and Chemical Hazards. The science of the Total environment $1: 86-98$

Sherif, A., Kaleb, K., and Birhanu, T., 2005. Facilitating sustainable agricultural technology transfer through farmer"s research group: The experience of DZARC. pp 67-70. Proceeding of workshop 20-21 October, 2004, MARC, Melkassa. 